\title{
LA GRAN MATANZA DE ANIMALES Y OTRAS EPIDEMIAS DE NUESTRA OBSOLETA MENTALIDAD INDUSTRIAL ${ }^{1}$
}

The great killing of animals and other epidemics of our obsolete industrial mentality

GUILLÉN, Jaime Torres ${ }^{2}$

Resumen: El artículo debate el concepto de mentalidad industrial partir del actual contexto del SARS-Cov-2 en relación con la gran matanza de animales en el presente sistema mundo capitalista. Se argumenta que a pesar de que las prácticas de la mentalidad industrial son obsoletas para revertir los riesgos globales que amenazan a la vida humana y no humana, esta se ha extendido culturalmente a manera de epidemia por todo el planeta. Para enfrentar esta mentalidad, la ciencia y la filosofía han resultado poco efectivas, por lo que el trabajo reflexiona sobre la necesidad de vincular las prácticas de la gente común con las herramientas de la convivencialidad propuestas por Iván Ilich.

Palabras clave: Mentalidad industrial. Apidemias. Animales no humanos. Convivencialidad.

\begin{abstract}
The article discusses the concept of industrial mentality from the current context of SARS-Cov-2 in relation to the great slaughter of animals in the present capitalist world system. It is argued that even though industrial-minded practices are obsolete to reverse global risks that threaten human and non-human life, it has spread culturally in an epidemic manner throughout the planet. To confront this mentality, science and philosophy have been ineffective, so the work reflects on the need to link the practices of ordinary people with the tools of coexistence proposed by Iván Ilich.
\end{abstract}

Keywords: Industrial mentality. Apidemias. Non-human animals. Coexistence.

\footnotetext{
${ }^{1}$ Recebido em: 07 Jul. 2020 | 30 Set. 2020

2 Universidad de Guadalajara, México. Correo: torresguillen@hotmail.com
} 


\section{Introducción}

De tortura a los animales está repleta la historia humana. Basta observar y leer The Four Stages of Cruelty de William Hogarth o leer algunas páginas de The criminal prosecution and capital punishment of animals de E. P. Evans (1906). El texto de Evans es relevante porque ofrece un amplio panorama histórico de la institucionalización religiosa y secular del castigo a cerdos, vacas, caballos, ratas, perros, ratones, langostas, variados insectos, gatos y un etcétera, en distintas épocas y lugares. El libro ofrece una panorámica amplia de cuál ha sido la relación de los animales humanos con los no humanos por lo menos en occidente. Es este un verdadero capítulo negro en la historia de la humanidad que historiadores y abogados desconocen o quienes están enterados quieren olvidar (Bondeson, 2000, p. 185).

Tuvo razón Robert Darnton (2015) cuando afirmó que la gente tortura a los animales en todas partes. (Darnton, 2015, p. 95) Sin embargo, le faltó decir que no siempre lo hace por los mismos motivos. El propio Darnton se pregunta porqué los obreros de la calle Saint-Séverin llevaron a cabo aquella "gran matanza de gatos" (Darnton, 2015, p. 88 y 96) cuestión por la cual se interesó en la historia de las mentalidades, esto es, la forma en que se construyó y se le dio significado al mundo, y por ende al comportamiento de la gente de la Francia del siglo XVIII. Es verdad, la crueldad con los animales era una escena cotidiana en la Francia de ese siglo, durante la época de la Reforma en Londres o en el mundo grecolatino. Pero la mentalidad que estudia Darnton, la cultura artesanal del Antiguo Régimen, no es la misma que aquella que motivó a los romanos o griegos del mundo clásico a castigar jurídicamente a los animales, ni la que motivó a la nobleza y cazadores de la Europa medieval y moderna a matarlos.

Por varios siglos, cada año en el Imperio Romano, "durante los 100 días de celebración de la consagración del Coliseo de Roma se mataron 9000 animales capturados, y otros 11000 para celebrar la conquista por parte de Trajano de la nueva provincia de Dacia (Ponting, 1992, p. 222); los juicios y ejecución de animales florecieron en Europa desde el siglo IV hasta el siglo XVIII (Bondeson, 2000, p. 186); las 
manadas de lobos que deambulaban en las calles de París entre el siglo XV y XVI motivó a Francisco I en 1520, a organizar cacerías oficiales (Ponting, 1992, p. 223).

[...] en 1533, el Parlamento inglés aprobó una ley (el Parlamento escocés había aprobado otra similar en 1424) por la que se exigía a todos los municipios tener redes para atrapar grajos, chovas y cuervos. Esta ley se amplió en 1566 para autorizar a los mayordomos de las iglesias a pagar por los cadáveres de zorros, turones, comadrejas, armiños, nutrias, erizos, ratas, ratones, topos, halcones, águilas ratoneras, quebrantahuesos, arrendajos, cuervos y maitines pescadores [...] En Wainfleet, Essex, en sólo un año se mataron 31, 200 patos a mediados del siglo XVIII. En una aldea de Lincolnshire, entre 1833 y 1868 se mataron una media de 3000 aves de caza anuales [...] En 1850 la gran mariposa cobriza se extinguió en Inglaterra porque la gente coleccionaba sus orugas [...] La demanda de plumas exóticas para sombreros en el siglo XIX hizo que en 1869 sólo Brasil exportase 170.000 aves muertas para arrancarles el plumaje, y en 1913 las salas de subastas de Londres pusieron en venta las plumas de 77.000 garzas, 48.000 cóndores y 162.000 martines pescadores [...] (Ponting, 1992, p. $225,226,229)$.

En 1871 en Norteamérica los europeos llegaron a matar 3 millones de bisontes al año para vender su piel. Hacia 1880 en Nueva Gales del Sur (Australia) debido a la afectación de la cría de ganado ovino se erradicaron casi 7 millones de conejos que habían sido introducidos tiempo atrás (Ponting, 1992, p. 234). "En 1743, el puerto francés de La Rochelle (uno de los centros del comercio con Canadá) importó 127.000 pieles de castor, 30.000 de marta, 12.000 de nutria, 110.000 mapaches y 16.000 osos" (Ponting, 1992, p. 246). Tan sólo por este fenómeno mundial, el del negocio de las pieles, que data por lo menos del siglo IX (Arnold, 2000, p. 115 y ss. Wolf, 2005, p. 196 y ss.) para finales del siglo XIX se "había reducido drásticamente la población de muchas variedades, y en grandes áreas se habían extinguido especies que en otro tiempo habían sido abundantes" (Ponting, 1992, p. 248). Con el tiempo tocó el turno a ballenas, focas, osos marinos, morsas y otras especies.

Un mismo acto, en este caso, la tortura y muerte a los animales, tiene distintas motivaciones. Desde un punto de vista de las mentalidades se podría decir que la gente actúa y justifica sus acciones, a partir de todo lo que le ofrece su medio. Las acciones orientadas por las mentalidades son prácticas, no se desprenden de manera mecánica de doctrinas religiosas, argumentos filosóficos o teorías científicas, sino que provienen de 
costumbres y creencias muchas de ellas basadas en narraciones, proverbios $\mathrm{o}$ supersticiones. Sirva el siguiente ejemplo para ilustrar lo anterior.

En un pasaje de "Las mentalidades. Una historia ambigua” (1974) Jacques Le Goff refiere el libro IV capítulo LXXVI de los Diálogos, del Papa Gregorio Magno quien narra la historia de un monje que hallándose moribundo confiesa no haber respetado la regla monástica de poner todo en común. La orden del abad fue que ningún monje lo visitara a ofrecer palabra alguna de consolación para que su muerte en la angustia fuera un ejemplo para los demás. Le Goff se interroga: “¿Por qué este abad, cultivado e instruido como pudiera serlo nadie entonces, no se dirigió más bien a la cabecera del pecador moribundo para abrirle la puerta del cielo con la confesión y la contrición?" (Le Goff, 1974, p. 85) la respuesta del historiador es que la mentalidad de la época sobre el castigo físico, se impuso a la doctrina cristiana del pecado, esto es, en la práctica, "la mentalidad venció a la doctrina" o a la teoría.

Una mentalidad es sin duda un fenómeno colectivo cuya expresión puede ser percibida en las creencias y las acciones de las personas en un tiempo espacio determinado. Bien se puede decir que las mentalidades no tienen un origen preciso o una fecha de inicio, sino que son producto de interconexiones y resonancias de narraciones, proverbios o creencias que, aunque provengan de lejos en el tiempo y en el espacio se insertan de manera prolongada en las prácticas de las personas. Por ello los contenidos de una mentalidad pueden permanecer, aunque algún paradigma o doctrina ideológica domine el escenario público de una determinada sociedad (Le Goff, 1974, p. 86).

Debo reconocer que así como lo hicieron Darnton y Le Goff en su disciplina, Lucien Febvre, Georges Duby o Robert Mandrou, trabajaron con mucha dedicación el tema de las mentalidades. Sin embargo, aunque este artículo se inspire en ellos, no desarrolla el concepto de mentalidad para abonar al campo de la historia. Sólo me sirvo de él en un sentido metodológico, a saber, que para comprender la gran matanza de animales en nuestras sociedades del siglo XXI y sus efectos nocivos, habría que analizar la orientación de dicho comportamiento a partir de un tipo de mentalidad que aquí llamaré: mentalidad industrial. 
Entiendo por mentalidad industrial creencias y prácticas que basan su acción exclusivamente en el beneficio particular. En términos filosóficos es una autodeterminación abstracta que marca las fronteras con lo comunitario y la alteridad por lo que su voluntad carece de contenidos morales que orienten su acción. Al permanecer en un estado formal, esta mentalidad abre las posibilidades para convertirse en arbitrariedad o en formas exageradas de individualismo. La mentalidad industrial existe sólo como deseo, terquedad o voluntad arbitraria. En términos normativos es una patología social que tiene su raíz en la absolutización de lo "particular" de la voluntad. ${ }^{3}$

Cabe señalar que la idea de maximizar la utilidad a un nivel particular de la que hablan los teóricos de la elección racional (Palmer, 1982; Elster, 2010) no es la mentalidad industrial. Los teóricos de la elección racional, aun con sus limitaciones (Ermakoff, 2019) desarrollan modelos para explicar el comportamiento humano a partir del supuesto de que los agentes son racionales. El comportamiento de un agente es racional "si satisface tres requisitos de optimalidad: la acción debe ser óptima, dadas las creencias; las creencias deben tener el mejor respaldo posible, dadas las pruebas; y las pruebas deben ser la resultante de una inversión óptima en la recolección de información". (Elster, 2010, p. 215). Ninguno de estos requisitos cumple la mentalidad industrial. Antes bien, como se verá, formaría parte del repertorio del autoengaño del que habla la teoría de la elección racional: creer lo contrario de la evidencia para evadirla (Elster, 2010, p. 160; Ermakoff, 2019, p. 219).

\footnotetext{
${ }^{3}$ No es este el lugar para ampliar la discusión filosófica del concepto. Baste por ahora decir que sigo la filosofía del derecho de Hegel quien desde $\$ 33$ de la Introducción a su Filosofía del Derecho (2005), establece el despliegue de la libertad en tres niveles de realización: abstracta, subjetiva y concreta. Es un despliegue de la cultura humana que va desde el ámbito privado (Derecho Abstracto) a la obligación de los deberes en términos formales (Moralität), hasta finalizar en la obligación concreta hacia la comunidad (Sittlichkeit). La mentalidad industrial puede entenderse como una subjetividad que limita toda obligación. "§ 138. Esta subjetividad, en cuanto abstracta autodeterminación y certeza pura de sí misma, disuelve en sí toda determinación del derecho, del deber y de la existencia, pues es el poder que para cada contenido juzga y determina exclusivamente desde sí qué es lo bueno, y al mismo tiempo el poder al cual debe su realidad al bien que un primer momento es sólo representación y deber ser." (Hegel, 2005, p. 236) Y también: "§ 139. Al establecer la vanidad de todas las demás determinaciones vigentes y permanecer en la pura interioridad de la voluntad, la autoconciencia es posibilidad de convertir en principio tanto lo en y por sí universal como el arbitrio, de hacer predominar la propia particularidad sobre lo universal, y de realizarla por medio de su actuar; en otras palabras, tiene la posibilidad de ser mala". (Hegel, 2005, p. 236) Para un estudio detenido sobre la moralidad en la filosofía del derecho de Hegel, véase: (Amengual, 2001)
} 
La gran matanza de animales en el actual sistema mundo capitalista, tiene en su base una paradoja propia de la mentalidad industrial. Por ejemplo, con eufemismo hoy se dice que se "sacrifica" a un gran número de animales para evitar la propagación de epidemias y por otro, para obtener utilidad o beneficios. Es decir, se dice que el sistema de ganadería intensiva trae beneficios, pero propaga enfermedades. Las grandes compañías productoras de carne como la Smithfield Foods han impuesto en el mundo un modelo de comer, matando a gran escala animales y al mismo tiempo eso nos está enfermando. En suma, la utilidad de matar animales en nuestras sociedades, produce enfermedades, razón por la que, a su vez, se mata a gran escala a animales.

El reciente artículo de Michael Corkery and David Yaffe-Bellany (2020) en The New York Times, ilustra la mentalidad industrial y la paradoja a la que hago referencia. Producto de la crisis sanitaria por el nuevo Coronavirus (SARS-CoV-2), dicen los periodistas, en las granjas de Minnesota, Estados Unidos, se estima que se han matado 90.000 cerdos debido al cierre de las plantas comercializadoras de carne. Con el cierre de estas plantas, se esperan más muertes de cerdos debido a que estos viven en función de un calendario comercial. La importancia de estas muertes, según lo documentado por los articulistas del The New York Times, es que los granjeros que han tenido que "sacrificar" grandes cantidades de animales han perdido hasta 390.000 dólares en un solo día. Centrarse en la pérdida económica y no en todo lo que implica la matanza de los animales en cuanto a salud, contaminación del agua, pastizales, deforestación o sufrimiento de estos, es una expresión de mentalidad industrial.

Sin duda una resonancia histórica de la mentalidad industrial proviene de lo que Marx y Engels llamaron en el Manifiesto Comunista, moderna sociedad burguesa (moderne bürgerliche Gesellschaft), ese comportamiento que cambió las pasiones por los intereses con el mito de que los vicios privados engendran virtudes públicas (Hirschman, 1978). Según Marx y Engels dicho comportamiento desgarró sin piedad las abigarradas relaciones premodernas y las ahogó en las "aguas heladas del cálculo egoísta”. Luego, a manera de mago, impuso mundialmente un tipo producción y consumo "que ya no es capaz de dominar las potencias infernales que ha desencadenado". Así creó una epidemia social (die Epidemie der Überproduktion) que amenaza su propia existencia. 
Conviene una aclaración. Aunque exista este vínculo con la moderna sociedad burguesa, no habrá que confundir mentalidad industrial con la creación de herramientas producto de la invención técnica y tecnológica en el periodo del siglo XIX y XX. De ninguna manera mi postura debe entenderse anti-tecnológica o anti-científica. Técnica es un saber hacer que implica, saber cómo y para qué. Lo mismo aplica para la tecnología, aunque esta sea un "tipo de técnicas productivas que incorporan conocimientos y métodos científicos en su diseño y desarrollo" (Quintanilla, 2005, p. 57) esto es, acción planificada, intencionalidad estratégica (exige fabricar máquinas que fabriquen máquinas, hacer herramientas para hacer herramientas), y cooperación. Por ejemplo, la tecnología para el control de la fusión nuclear, la ingeniería genética, la tecnología láser, la arquitectura o cirugía (Broncano, 2000, p. 91 y ss.); o las tecnologías basadas fundamentalmente en habilidades manuales, artesanía, oficios; o en habilidades organizativas como la gestión de empresas o instituciones (Quintanilla, 2005, p. 100).

Pero sí hay que enfatizar que en la época en que vivimos, la técnica y la tecnología se realizan dentro de una mentalidad industrial. Contrario a lo que se piensa de manera común, no son estas las que configuran de manera mecánica a la sociedad, sino la sociedad (mentalidad industrial) es la que condiciona a aquellas. Es verdad que los artefactos tecnológicos innovan y abren horizontes de los posibles contenidos del futuro de las sociedades (Broncano, 2000, p. 36), pero en el proceso histórico de la mentalidad industrial tienen dos dimensiones que resulta una paradoja: el ser útiles y al mismo tiempo malos.

En efecto, las herramientas tecnológicas pueden ser útiles a los individuos particulares pero nocivas para la comunidad y el medio ambiente. Por ejemplo, el glifosato es una herramienta, específicamente, un herbicida utilizado en agricultura, silvicultura o jardinería. Podemos decir que es útil al bolsillo de los accionistas de Monsanto, Chemical Industry Company, Bayer o DuPont; o decir que es una tecnología derivada de un invento químico, pero que es tóxico a la vida en general. ${ }^{4}$ Lo mismo el arsénico, el clordano, el heptacloro, o el dieldrín (Carson, 2017, p. 17 y ss.).

\footnotetext{
${ }^{4}$ Sobre la nocividad del glifosato véase: (https://glyphosatestudy.org/es/about-us/)
} 
Ahora bien, si se sabe que una determinada tecnología es útil pero al mismo tiempo mala, ¿Qué es lo que permite que se siga reproduciendo? Frente a esto los filósofos tienen respuestas: consideran que se debe a la carencia de valores en las actividades tecnológicas o una falta de conciencia ética en esta. Por eso dicen que una nueva ilustración en la que la política se subordine a la ciencia y a la tecnología podría ser la solución (Mitcham, 1990); o que una racionalidad comunicativa y deliberativa combinada con una alfabetización científica y tecnológica de la ciudadanía podría sentar las bases para la unidad entre tecnología y valores (Broncano, 2000, p. 233).

En este artículo exploro otra vía. Afirmo que parte de la respuesta a esta pregunta radica en nuestra obsoleta mentalidad industrial convertida en una epidemia, en una infección cultural extendida. Es obsoleta porque sus prácticas son inadecuadas para la situación de emergencia planetaria en que nos encontramos. Nuestra mentalidad industrial tiene como base una perspectiva simplificadora de la realidad. En su deseo y terquedad por encontrar beneficios inmediatos, se apresura a lo fácil, útil y práctico a partir de una visión particular del mundo. A ser una patología social, se expande como epidemia a todos los campos de la cultura, la política, la ciencia, los negocios, el mercado o la educación, que al generalizarse como acción está destruyendo la vida humana y no humana.

En la crítica a la mentalidad industrial, tomo el ejemplo de la gran matanza de animales y las actuales epidemias, especialmente el SARS-CoV-2, no como un caso cualquiera, sino como un fenómeno al que se debe prestar atención si realmente se quiere discutir en serio el peligro en que se encuentra la vida en general; si se quiere tomar en serio los valores de la equidad, la solidaridad y el cuidado; incluso si se quiere tomar los derechos en serio. Parafraseando a Karl Polanyi (Polanyi, 2014, p. 337-8), afirmo que hoy, nos enfrentamos con la tarea vital de rehabilitar una práctica normativa que tome en cuenta la vida en general, no solamente la humana, aunque esto suponga una sociedad tecnológicamente menos eficiente.

El artículo se divide en tres partes, en la primera, argumento que las actuales epidemias que padecemos, tienen su origen en los mataderos de animales y aunque existe un consenso científico sobre ello, la mayoría de científicos no llama a detener la industria global de la carne. Sostengo que en este caso la mentalidad industrial, en la 
práctica vence al conocimiento científico por lo que tal conocimiento, no tiene la fuerza suficiente para enfrentar esta patología social. La segunda parte esboza cómo la filosofía guarda todo un arsenal de sabiduría, que, en el campo de las ideas es capaz de cuestionar y vencer las creencias o narraciones de la mentalidad industrial, pero que en la práctica, esta mentalidad es inmune a dicha sabiduría por lo que para el tema que trato, la filosofía aparece como una ilusión.

En el apartado tercero discuto un camino para enfrentar los efectos de la mentalidad industrial, en especial la pandemia del SARS-Cov-2 y la gestión empresarial de esta que han desplegado gobiernos y corporativos mundiales. Argumento que si la mentalidad industrial se sostiene en sus prácticas, sólo otras prácticas basadas en la moralidad de la gente común y las herramientas de la convivencialidad propuestas por Iván Ilich, podrían hacer frente a la catástrofe que ya está aquí. En el apartado, la crítica a la medicina industrial y una rehabilitación de la idea de salud como cuidado son parte sustantiva de su contenido.

\section{Epidemias: el Chernóbil de la carne}

Michael B. A. Oldstone (1998) llamó la atención cuando afirmó que los conocimientos que se tenían en siglo XIX y principios del siglo XX, sobre los microorganismos que causaban enfermedades infecciosas a la población humana, generó profecías sobre el poder del hombre para acabar con las plagas que lo habían atacado en el pasado. Sin embargo, continuó Oldstone, "en 1926, cuando se publicó el libro clásico de Paul deKruif Microbe Hunters, casi todas las enfermedades virales continuaron sin cesar y sin descanso cobrando víctimas" (Oldstone, 1998, p. 187).

Lo mismo podríamos decir en el 2020: cuando se publicó Virus: The Co-discoverer of HIV Tracks Its Rampage and Charts the Future de Luc Montagnier o cuando se logró diseccionar la arquitectura del genoma de ARN del SARS-CoV-2, casi todas las enfermedades virales seguían activas y algunas de ellas cobrando víctimas como el SIDA y el SARS-CoV-2. 
En realidad, la idea de terminar de manera definitiva con los virus y las enfermedades infecciosas proviene de una mentalidad industrial. Hay quienes a propósito del SARS-CoV-2 hablan de un retorno de las plagas como si la profecía industrial del poder humano hubiera fracasado. 0 suponen, de manera alarmista, un determinismo ambiental al afirmar que el espacio global donde son cada vez más cercanos los intercambios entre humanos, no humanos, mercancías e ideas, es el ambiente propicio para nuevas epidemias (Buj, 2005; Menchero, 2020, Saracho, 2020).

Las epidemias y pandemias no son algo extraordinario en la vida humana, sólo una mentalidad industrial es capaz de obsesionarse por la inmunidad definitiva de la especie humana. Entre otros factores, la complejidad anatómica y funcional del homo sapiens siempre evitará la "salud perfecta" (Pérez, 1998, p. 12). Además, la relación entre especies es una realidad en la biósfera por lo que toda zoonosis (infección trasmitida entre especies animales) nos recuerda que los humanos somos animales, estamos ligados a esta condición en el origen, filogénesis, desarrollo, salud y enfermedad. (Quammen, 2020: Capítulo I, sección 1, párr. 3).

Esto lo saben bien los ecólogos veterinarios, epidemiólogos y virólogos porque además de estudiar de manera sistemática este fenómeno, reconocen la íntima conexión biológica entre seres humanos y naturaleza en general. Basta consultar el National Library of Medicine y la National Center for Biotechnology Information para enterarse que la mayoría de las enfermedades infecciosas pasan de animales no humanos a animales humanos y viceversa porque los virus evolucionan rápido y, para el caso de los humanos, son inmunes a los antibióticos (Crawford, 2000; Holmes, 2009; Doherty, 2019). Si a ello le agregamos que nuestro acercamiento a microorganismos capaces de enfermarnos aumentó con la domesticación de animales (Ponting, 1992, p. 304), lo extraordinario pierde valor y se entiende la noción de epidemia y enfermedad en términos sociales y culturales. ${ }^{5}$

Durante el siglo XX y lo que llevamos del XXI, la zoonosis es un fenómeno de interés para la epidemiología y la veterinaria porque afectó a los humanos de manera

\footnotetext{
5 Por ejemplo, las epidemias en parte explican la desaparición de las civilizaciones mesoamericanas en las cuales la domesticación de animales era una práctica inferior a la de los europeos que trajeron consigo las infecciones con las que acabaron con numerosas poblaciones en la antigua América. (McNeill, 1976, p. 178 y 179; Ponting, 1992, p. 312)
} 
considerable. Se piensa que la gripe española (1918) saltó a los humanos de un ave o cerdo; la Fiebre de Lassa (1969) por exposición con orina o heces de roedores; la Fiebre hemorrágica de Marburgo (1967) y el Ébola (1976) por algún contacto con chimpancés, gorilas, murciélagos frugívoros, monos, antílopes y puercoespines infectados. Y así podemos seguir con el VIH (1981), el cual ha matado 30 millones de humanos y están contagiados hasta el 2020, 34 millones (Quammen, 2020: Capítulo I, sección 6, párr. 9), el virus Hendra (1994) que afecta a humanos y a caballos, la Gripe Aviar (1997), el virus Nipah (1998), el SARS (2003), la Gripe Porcina o H1N1 (2009) y el actual SARS-CoV-2 (2020). ${ }^{6}$ Cabe resaltar que al no existir vacuna para la mayoría de estas enfermedades y afectar cada vez más a la población mundial, sobre todo de países metropolitanos, este fenómeno tiene mayor presencia en la prensa y los organismos internacionales de salud.

Sin embargo, producto de la mentalidad industrial, en los últimos años, este saber ha generado un motivo para la gran matanza de animales, sumado al que ya existe en la industria de la carne. En 1997, un millón y medio de aves de corral fueron exterminadas en Hong Kong luego de conocer la zoonosis que desencadenó la gripe aviar en humanos (Quammen, 2010: Capítulo IV, sección 36, párr. 2). En 1999, según The Center for Food Security and Public (2016), en Malasia más de un millón de cerdos fueron eliminados de la faz de la tierra por temor al contagio del virus Nipah. En 2004, el gobierno chino ahogó, incineró y electrocutó a diez mil civetas de palma, luego que se supo que este mamífero estaba relacionado con el virus del SARS; entre 2003 y 2004 en Asia se exterminaron 140 millones de aves (Nierenberg, 2006, p. 88); en 2005, en el estado de Winconsin, Estados Unidos, por temor a la transmisión de la enfermedad de CreutzfeldtJakob y el miedo a que se paralizara la industria de caza de venados se aniquiló a 25, 000 venados (Diamond, 2019, p. 86); y en 2009 en Holanda, cincuenta mil cabras fueron exterminadas para evitar contagios de la fiebre $Q$.

En el caso de las civetas, a pesar que los estudios científicos argumentaban que estos animales podían ser sólo la fuente inmediata del virus que se encuentra en los seres humanos, porque las pruebas indicaban que el virus provenía de otro reservorio (Wenhui Li et. al, 2006), con esta matanza, las personas y las autoridades se sintieron a

${ }^{6}$ Sin contar la viruela símica, la tuberculosis bovina, la enfermedad de Lyme, La fiebre amarilla, la fiebre del Nilo Occidental, la Rabia, el Ántrax o la fiebre hemorrágica boliviana. 
salvo. En otras palabras, las y los científicos encontraron que las civetas no eran el reservorio del SARS, sino un huésped amplificador, pero la mentalidad industrial optó por declararlas chivos expiatorios y con ello se sintieron fuera de peligro. Aunque no fueron juzgadas formalmente como los casos que muestra E. P. Evans en su libro, en los hechos fueron declaradas culpables.

La visibilización de epidemias producto de zoonosis, está generando un prejuicio que a su vez invisibiliza la responsabilidad que sobre este fenómeno tiene la industria global de la carne. Hay quienes (Wolfe, Daszak, Kilpatrick y Burke, 2005; Quammen, 2020) sugieren que las nuevas epidemias por zoonosis provienen de "la era de los sabores silvestres", ese fetiche por experimentar cocinas exóticas como el tejón porcino, perro mapache o civeta, junto la falta de higiene en los mercados asiáticos. Se imaginan el origen de las enfermedades infecciosas como el SARS o SARS-CoV-2, en una aldea remota llena de animales salvajes, que luego los turistas internacionales llevan a "la civilización" (Menchero, 2020).

Es verdad que la caza de gorilas y la ingesta de animales salvajes está relacionado con enfermedades virales (Wallace, 2020) como es el caso del Ébola (Quammen, 2020: Capítulo II, sección 19, párr. 1), pero señalar por ejemplo, que en Ouésso, localidad de la República del Congo, se comercialicen miles de kilos de carne de monos, cocodrilos, chimpancé o gorilas (Quammen, 2020: Capítulo VIII, sección 101, párr. 8) como un reproche de "la civilización" a estas prácticas, es olvidar que la zoonosis está en potencia en todas partes donde exista la gran industria de la carne.

Existen numerosas advertencias sobre el peligro para la salud humana y al medio ambiente, que representan esta industria (Nierenberg, 2005; Vivas, 2012; Riechmann, 2012, Wallace, 2016), incluso desde las organizaciones del sistema mundo capitalista. Por ejemplo, la FAO ha puesto énfasis no sólo en la degradación de las tierras y pastizales, contaminación atmosférica, contaminación del agua, impacto en los recursos hídricos y en el cambio climático, derivado de la industria ganadera, sino en la transmisión de organismos patógenos a través de esta. (Steinfeld, 2009, p. 222) La OMS también se ha manifestado al respecto y "la Organización Mundial de Sanidad Animal (OIE) estima que no menos del 60 por ciento de los patógenos humanos y del 75 por ciento de las enfermedades de reciente aparición son enfermedades zoonóticas" 
(Steinfeld, 2009, p. 304) por lo que el potencial de la industria ganadera para desarrollar y transmitir enfermedades epidémicas es una realidad.

Entonces, las actuales epidemias producto de zoonosis no se derivan exclusivamente de la "era de los sabores silvestres"7 ni son "desastres naturales" como las definen gobiernos, autoridades sanitarias, ganaderos y medios de comunicación, sino efecto, de una práctica derivadas de nuestra obsoleta mentalidad industrial: matar animales a gran escala. La industria mundial de la carne ha desarrollado las condiciones idóneas para ello (Nierenberg, 2006, p. 86; Wallace, 2016) y pese a esto, su desarrollo no disminuye.

Desde 1961 el número de reses ha aumentado en el mundo un 38\%, de 3.100 millones a más de 4.300 millones. La cabaña más numerosa se encuentra en la India y en China: India tiene alrededor de 185 millones de vacas, cerca del $14 \%$ del total mundial y China alberga la mitad de los más de 950 millones de cerdos del mundo. A su vez, el número de aves de corral se ha multiplicado por cuatro desde 1961: de 4.200 a 17.800 millones de aves (Nierenberg, 2006, p. 73).

La producción mundial de carne es el nuevo Chernóbil que nadie quiere ver. Aunque por todos lados se crían cabras, ovejas, vacas, gallinas y otros animales, es la ganadería industrial (Tyson Foods, Pilgrim's Pride, Smithfields Foods por ejemplo) la que produce "el 74\% de las aves, el 50\% del porcino, el 43\% del vacuno y el 68\% de los huevos del mundo" (Nierenberg, 2006, p. 78) y cuyas ganancias rondan en los 10.000 millones de dólares anuales. ${ }^{8}$ Nuestro acercamiento riesgoso a agentes patógenos es un efecto de las prácticas de nuestra mentalidad industrial, porque al mismo tiempo que se satisface un deseo particular o se obtienen rentas jugosas para la gran industria ganadera, favorecemos la evolución de bacterias resistentes y virus desconocidos para la

\footnotetext{
${ }^{7}$ Zhongshán es un ciudad prefectura en la provincia de Cantón, en la República Popular China. Situada al sur del delta del río Perla. Su área es de $1800 \mathrm{~km}^{2}$ y su población es de 3,1 millones. El nombre de la ciudad es un epónimo de Sun Yat-sen, también conocido como zhongshan. Se venden serpientes, zorros, civetas, ratas, cigüeñas, gaviotas, grullas, gatos, ardillas voladoras, tortugas, sapos, murciélagos de la fruta.

${ }^{8}$ Cabe resaltar que la producción intensiva de animales no comenzó en el siglo XX, por lo menos se sabe que en Europa desde el siglo XVI las "técnicas ganaderas" (hacinar, encadenar, enterrar, alimentar con otros animales a los animales de consumo, etc.) se aplicaban para aumentar la productividad de la carne (Ponting, 1992, p. 335 y 336).
} 
ciencia (Quammen, 2010: Capítulo IX, sección 115, párr. 14). He ahí la paradoja de la mentalidad industrial, opta por lo útil y al mismo tiempo por lo malo.

Frente a esta realidad, la respuesta de los complejos industriales empresariales, ciertos magnates y gobiernos en general, es acabar con las enfermedades que pueden producir epidemias o pandemias a través de vacunas, mayor inocuidad en la industria cárnica y el "sacrificio" de animales enfermos. Pero habría que cuestionarles si eso significa que su cruzada contra los virus pasa por exterminar a todos los huéspedes reservorio, o en su defecto, van a utilizar toda la maquinaria de la tecnología médica para tratar y curar a todos los animales no humanos que son huéspedes reservorio o huéspedes amplificadores. Esta pregunta expone la obsoleta mentalidad industrial que gobierna.

Por su parte, los epidemiólogos, virólogos, ecólogos y veterinarios saben que la zoonosis es potencial en todos los sistemas de ganadería intensiva que hay en el mundo. Están enterados que esta práctica posibilita las epidemias y al mismo tiempo siguen razonando en términos de mentalidad industrial: alertan de enfermedades provenientes de la carne, pero hay quienes no recomiendan su disminución (Denner, 2019) o su desaparición (Medellín y Suro, 2020). En sus juicios está el recomendar la capacitación en materia de bioseguridad y protección biológica para mitigar las amenazas de virus emergentes en las industrias ganaderas (Borkenhagen, Salman y Gray, 2019). Además, aunque conocen bien los daños al medio ambiente y la salud personal, derivados del consumir carne (Appleby y Key, 2016) no se atreven a cuestionar la totalidad del sistema industrial ganadero.

Parafraseando a Le Goff ¿Por qué las y los científicos, en su gran mayoría, cultivados e instruidos como pudiera serlo nadie en estos momentos, como comunidad no emiten juicios normativos sobre la necesaria disminución o en el mejor de los casos, desaparición de la producción industrial de carne, derivado del conocimiento riguroso que realizan? Respuesta: en la práctica, la mentalidad industrial se impone al conocimiento científico. En este caso, la mentalidad vence a la ciencia. Además, como lo afirmó Ulrich Beck:

Las ciencias, tal como están concebidas -en su división sobreespecializada del trabajo, en su comprensión metódica y teórica, 
en su abstinencia práctica ajenamente determinada-, no están en situación de reaccionar adecuadamente ante los riesgos de la civilización, ya que se forman y participan de manera notable en el crecimiento de estos riesgos. Más bien las ciencias devienen -en parte, con la buena conciencia de la «cientificidad pura», en parte, con el creciente remordimiento de conciencia - en un protector legitimador del embrutecimiento y envenenamiento industriales a escala mundial del aire, agua, alimentos, etc., así como de la caquexia y muerte generalizadas y vinculadas a ello de plantas, animales y seres humanos (Beck, 1998, p. 66).

Por su parte las llamadas ciencias sociales o el denominado pensamiento social, está ausente en este debate. No quiere decir que no se expresen, sino que no poseen la hegemonía del discurso técnico de las ciencias naturales sobre las epidemias, pandemias o catástrofes. Lo que digan no impacta de manera pública. Si a esto le sumamos otra ausencia, a saber, el desinterés de la sociología o la antropología por disputar dicha hegemonía, el cuadro se completa: los conocimientos sobre los peligros planetarios se limitan a sus componentes teóricos o metodológicos, nunca a sus componentes normativos.

Termino este primer apartado. Las epidemias que se propagan con rapidez, una de ellas ya en calidad de pandemia, el SARS-CoV-2, provienen principalmente del Chernóbil que ha creado la industrial global de la carne. La gran matanza de animales es una epidemia en dos sentidos, no sólo porque está extendida en el planeta como práctica sistemática, tecnológica y cultural, sino porque a su vez crea las condiciones para las enfermedades zoonóticas que ya se conocen y las que están por venir (Garrett, 2006; Ribeiro, 2020).

\section{Contrarrestar la mentalidad industrial. Sabiduría e ilusiones de la filosofía}

Existe en el campo de las ideas, especialmente la filosofía, argumentos suficientes para cuestionar las prácticas de la mentalidad industrial la cual nos está llevando al desastre. A propósito del tema que aquí trato, la gran matanza de animales, el pensamiento contemporáneo (de Lora, 2003, Riechmann, 2005; Wolf, 2012, Mosterín, 2014, Regan, 2016) recurre a los filósofos para cuestionar la inmoralidad de los placeres crueles como el comer carne (Tolstoi, 1902, p. 152;), reflexionar sobre nuestros deberes 
hacia los animales (Hume, 1977, p. 687) y sobre su sufrimiento (Bentham, 1979, p. 282) causado por la tortura que le propinamos los humanos (Schopenhauer, 1967, p. 97). Este pensamiento reconoce en las buenas razones que ha aportado la filosofía, elementos para cuestionar la crueldad contra los animales y los efectos nocivos de esta (Lucano, 2017). Pero, aunque también este tipo de pensamiento tiene sus ideas propias, sus conclusiones siguen el clásico esquema filosófico que termina en una discusión moral o ética de corte académico.

En efecto, desde sus inicios, la filosofía occidental se ocupó de esos temas con mucha seriedad por lo que se tiene todo un acervo de conocimiento al respecto. Por ejemplo, en la filosofía clásica occidental Plutarco (2002) y Porfirio de Tiro (1984) pertenecen a ese acervo. La argumentación filosófica de Plutarco y Porfirio sobre el acto de comer carne y el matar animales, contienen razones plausibles para la formación en la sabiduría de la frugalidad y la sencillez de la vida humana, aspecto relevante para reorientar el rumbo de nuestra civilización. Para ambos, matar animales para comerlos es insensato (Plutarco, 2002, p. 383; Porfirio, 1984. P. 77) porque además de causarles sufrimiento, esa acción genera "despilfarros, enfermedades, hartazgos y vagancias" (Porfirio, 1984: 79). Este acervo filosófico se multiplicó con el paso del tiempo a través de discusiones retóricas, escolásticas, lógicas, éticas o normativas, hasta llegar a la actualidad a los debates bioéticos (Lucano, 2017).

Sin embargo, en su gran mayoría estas reflexiones filosóficas abordan temas que van desde el virtuosismo ascético hasta la actitud ética de las personas, con el objetivo pedagógico de formar conciencias y modificar comportamientos nocivos entre los humanos y de estos hacia la naturaleza. Por ejemplo, con el ejercicio intelectual de la filosofía, aparece una dimensión crítica capaz de pensar el descentramiento de la especie humana y su apertura a la alteridad. Es verdad, en los contenidos de esta disciplina existe sabiduría, sin embargo, es una ilusión creer que esta pueda ser la llave para contrarrestar la mentalidad industrial. Si la mentalidad industrial es inmune al conocimiento científico, también lo es ante la reflexión filosófica.

Eso lo observaron con suma precisión Th. W. Adorno y Max Horkheimer quienes diagnosticaron en Dialéctica de la Ilustración que la violencia a los animales no humanos en las sociedades industriales, es ciega, mecánica y automática (Adorno y Horkheimer, 
2005: 291). Este diagnóstico es pertinente para comprender el fracaso de la filosofía ante la mentalidad industrial, en especial, el de la filosofía crítica. En la cultura de masas, como le llamaban estos filósofos a la mentalidad industrial, se vive del horror y eso "está en relación también con el comer carne" (Adorno y Horkeheimer, 2014: 71). En medio de ese horror, no es posible imaginar lo mejor o la vida buena como pensaban los filósofos clásicos o las actuales reflexiones éticas de las y los filósofos, porque la mentalidad industrial no capta el desastre (cree lo contrario de la evidencia) ni imagina la felicidad. Es persistente en el error y la estupidez. Además, como la base de sus prácticas no proviene de doctrinas o teorías, sino de narrativas y creencias, es iluso pensar que la filosofía le pueda hacer frente.

La sociedad libre con la que soñaba Herbert Marcuse, aquella que para serlo debía "reducir consistentemente el sufrimiento que el hombre impone al mundo animal" (Marcuse, 1973: 80) suponía la instauración de la razón en el mundo. Esto es, por medio de la toma de conciencia colectiva, a través de la filosofía, podríamos superar y liberarnos de las sociedades industriales avanzadas (Marcuse, 2011: 29) que todo controlan y destruyen. Pero la filosofía crítica de Marcuse no tomaba en cuenta la mentalidad industrial, seguía el manual marxista el cual entendía el déficit de razón en la era de las sociedades avanzadas, como falsa conciencia. Por tanto, postulaba su superación por medio de la praxis del sujeto. Lamentablemente la filosofía crítica cuando hablaba de sociedad libre y praxis del sujeto, seguía un patrón metafísico al distanciarse de las prácticas reales derivadas de la mentalidad industrial.

Lo más interesante de la filosofía crítica era su discurso sobre la imaginación creadora capaz de hacer converger ciencia, tecnología y arte para liberar a la sensibilidad humana, atada a la burocratización y administración capitalista de nuestras vidas. Esa imaginación creadora es a la que llegó Rosa Luxemburgo cuando en sus cartas de prisión aseguraba que en su lucha revolucionaria se sentía más cerca del sufrimiento de las aves que de sus camaradas (Luxemburgo, 2019: 224).

En efecto, esta imaginación creadora es parte del legado de la reflexión filosófica y contiene grandes enseñanzas y sabiduría. Pero frente a la mentalidad industrial es una ilusión porque no logra contrarrestar las prácticas nocivas de aquella. Por esto es sintomático que, hasta el momento, filósofos de todas las corrientes, incluso corrientes 
filosóficas opuestas como la de Mario Bunge y Jacques Derrida, aboguen por la disminución del sufrimiento de los animales (Bunge, 1976: 56) o crean que "Esa violencia [contra los animales] industrial, científica, técnica, no puede soportarse todavía demasiado tiempo, de hecho o de derecho" (Roudinesco, 2009: 77). En realidad la sabiduría de ambos filósofos es para la mentalidad industrial, una ilusión.

Sostengo que contrarrestar la mentalidad industrial no podría derivarse de manera mecánica de una filosofía, sea esta crítica o de aquella que demande argumentos y buenas razones contra la gran matanza de animales y el riesgo a la vida en general que esta práctica representa. Las mentalidades no tienen su base en una teoría o doctrina, son prácticas de la gente común, es decir, todas y todos los que habitamos un mundo. Si esto es así, solo otras prácticas pueden contrarrestarla, una de ellas podría ser las prácticas que se derivasen de la convivencialidad.

\section{El mundo que viene: gestión empresarial de la pandemia y práctica de la convivencialidad}

Nuestra mentalidad industrial además de ser obsoleta, inmune a la ciencia y a la filosofía, nociva para la vida en el planeta, es también el mayor obstáculo para construir otro mundo. Esto puede percibirse en el actual contexto de pandemia por SARS-CoV-2. Derivada de esta mentalidad, en los últimos meses ha aparecido una retórica del optimismo: se habla de que el mundo se ha vuelto más solidario y caritativo, que la pandemia nos ha enseñado a ser más generosos y ha sacado lo mejor de nosotros. Es el tipo de sentimentalismo que explota la gran industria del entretenimiento, las empresas $\mathrm{y}$ algunas iglesias que predican el amor abstracto.

En realidad, después del fracaso del marxismo y los movimientos revolucionarios del mundo, no existe hasta el momento rutas que permitan vislumbrar trasformaciones históricas al mundo capitalista. Y no existen porque no las hemos construido. Somos dependientes de quienes gestionan y consumen empresarialmente nuestra vida. Un claro ejemplo es cómo los multimillonarios estadounidenses aumentan sus ganancias a medida que empeora la situación en el mundo por SARS-CoV-2. Según el nuevo informe 
del Institute for Policy Studies y Americans for Tax Fairness, los más de 600 multimillonarios estadunidenses incrementaron sus ganancias en un 15 por ciento durante el periodo que llevamos de pandemia. Los cinco multimillonarios más ricos: Jeff Bezos, de Amazon; Bill Gates, de Microsoft; Mark Zuckerberg, de Facebook; Warren Buffett, de Berkshire Hathaway; y Larry Ellison, de Oracle, obtuvieron los mayores incrementos en un total de 3.382 billones de dólares (Collins, 2020).

Esto es una muestra del mundo que viene. Con gran velocidad numerosas empresas, instituciones y organizaciones en general están incursionado en el mundo digital que dominan estos multimillonarios. El caldo de cultivo para conocer el comportamiento de las personas generará clientes tipo a los cuales ofrecer mercancías a su medida. Estos mundos artificiales que se están creando no terminarán con el capitalismo, sino que modificarán la forma en que se mediará el fetiche del valor en las relaciones sociales. La mentalidad industrial seguirá su curso como alguna vez lo planteara Ulrich Beck (1998) en sus 5 tesis con las que explicita la conformación de la arquitectura social y la dinámica política de los potenciales autodestructivos de nuestra civilización:

a) Los niveles más avanzados de las fuerzas productivas generan riesgos sistemáticos, irreversibles, invisibles y sin posibilidad de analizarlos normativamente; $b$ ) El reparto global de los riesgos produce situaciones sociales de peligro en todas las capas de las poblaciones sin distinción; c) “[...] la expansión de los riesgos no rompe en absoluto con la lógica del desarrollo capitalista, sino que más bien la eleva a un nuevo nivel. Los riesgos de la modernización son un big business" (Beck, 1998, p. 29); d) Se sabe que el peligro es real y afecta a todos, por lo que se gesta una "teoría del surgimiento y difusión del saber de los riesgos"; e) Al generarse una disputa pública por la definición de los riesgos, los estados y corporativos pueden normalizar el estado de excepción (Beck, 1998, p. 30).

El axioma $a$ y $b$ están en curso desde hace bastante tiempo, el axioma $c$ se expresa actualmente en la retórica del optimismo. Predicada por la gestión empresarial, este axioma profetiza que vendrán cambios en la educación y los negocios que beneficiarán a las nuevas generaciones. Y aunque se explote en la prensa los análisis de la "crisis económica" o la recesión que se avecina producto de la actual pandemia, se continuará 
con la invisibilización del agravio moral que ocasiona el desempleo, la dura vida de las y los jornaleros, de las y los trabajadores de la industria y los servicios, las y los migrantes; las heridas ocultas del personal sanitario y de la higiene pública, lo cual si se observa con detenimiento, también es una epidemia.

Es desde esta retórica del optimismo, que se puede observar el patrón que seguirán gobiernos y grandes empresas (axioma $d$ y $e$ ): gestionar de manera particular la pandemia del SARS-Cov-2. Si no fuera así, los gobiernos y los grandes complejos militares y empresariales pondrían a disposición la tecnología e insumos necesarios, las pruebas PCR (Polymerase Chain Reaction) ${ }^{9}$ para saber quién tiene el virus y a dónde lo lleva, como dice la epidemióloga Margaret Harris (Sotomayor, 2020, p. 6 y ss.), de esta manera las cuarentenas y todas las medidas sanitarias para aislar al virus y evitar multiplicar contagios tendría sentido porque tendrían como misión identificar los brotes y cercar la posible propagación del virus. El principio sería el cuidado colectivo de la vida.

En sentido contrario, los dueños del dinero y los intoxicados de la industria de masas presionan por volver "a la normalidad" sin plantear ningún cambio sustantivo en la manera en que realizamos la cotidianidad. Siguen pensando en términos de progreso a pesar que como señala Ignacio Ramonet, frente a la actual pandemia, de nada ha servido la espectacular supremacía tecnológica (teléfonos inteligentes, drones futuristas, robots, biotecnologías, biomedicina) de la que presume el sistema mundo capitalista: los contagios en el mundo por SARS-CoV-2 avanzan a gran velocidad. Lo irónico es que para contener la pandemia los y las expertas de los gobiernos se limitan a recomendar la higiene básica constante o "recurrir a productos y a técnicas viejos de varios siglos atrás. Respectivamente: el jabón, descubierto por los romanos antes de nuestra era; la máquina de coser, inventada por Thomas Saint en Londres hacia 1790; y, sobre todo, la ciencia del confinamiento y del aislamiento social, afinada en Europa contra decenas de oleadas de pestes sucesivas desde el siglo V" (Ramonet, 2020).

\footnotetext{
${ }^{9}$ Prueba de diagnóstico que permite detectar un fragmento del material genético de un patógeno. La PCR localiza y amplifica una molécula de ARN de coronavirus. Así se detecta si una persona con un cuadro de malestar respiratorio está infectada por el SARS-CoV-2. Si no se detecta el material genético del virus, la persona no estaría infectada. Las pruebas pueden repetirse para tener certeza de la infección positiva o negativa en un paciente.
} 
Tiene razón Ramonet al afirmar que la pandemia es un "hecho social total" al estar vinculado a ella lo biológico, lo psíquico, lo histórico y lo social, de la acción individual y colectiva. La sociedad global, sus instituciones y las relaciones cotidianas están sujetas a esta condición. El riesgo del colapso, esto es, no sólo la disminución drástica de la población humana y/o sus sistemas culturales, políticos y sociales complejos durante un periodo prolongado (Tainter, 1988, p. 4; Diamond, 2019, p. 23), sino la destrucción de hábitats, suelos, bosques, praderas, animales y la vida en general, es una realidad. Pero nada de eso importa, la mentalidad industrial quiere una "nueva normalidad". Volver a la productividad sería la palabra en términos de mentalidad industrial o gestión empresarial. Con esto se entiende mejor la presión de la industria automotriz en México a la que no le interesa el riesgo a la salud del nuevo virus, sino el riesgo de perder la inversión extranjera en el país (Cruz, 2020, p. 20 y ss.).

Ahora bien, si los gobiernos y los complejos industriales empresariales van a gestionar de manera particular la pandemia, es decir si actuarán desde su mentalidad industrial y si la ciencia y la filosofía no pueden contrarrestar las prácticas nocivas que originan a esta ¿Qué podemos hacer? Una respuesta podría ser buscar en las prácticas de la gente común. Si la mentalidad industrial se compone de prácticas, es posible hacerle frente con otras prácticas que pudiesen detener el colapso.

Para esto, escudriñar la historia siempre deja algún aprendizaje. A propósito de las epidemias del pasado, la gente común generó prácticas para la salud que quedaron en el olvido en buena medida porque el discurso de la historiografía de la medicina las ocultó. Como lo demostró Mary Lindemann (1999), los historiadores de la medicina generaron la idea falsa de que antes de la profesionalización médica existía un vacío en la cuestión de la salud. Lo cierto es que antes de la medicina industrial ${ }^{10}$ el paisaje social respecto al sanar era muy diversificado: "cirujanos, parteras, curanderos, dentistas, litotomistas [personas con habilidad para extraer cálculos de vejiga], boticarios, pastores y gente común que se ocupaban de la medicina ya sea como parte de sus tareas

\footnotetext{
10 Llamo medicina industrial a las prácticas instrumentales que tienen el objetivo de tratar enfermedades y concebir la cura en términos utilitaristas. Esta mentalidad, en la práctica, inhibe toda capacidad creativa y normativa de las personas para el autocuidado y el de los demás, porque su punto de partida es el interés privado.
} 
domésticas normales o como expresiones de buena vecindad" (Lindemann, 1999, p. 232).

Lindemann descubre que en el período de 1500 a 1800, en Europa, la medicina estaba integrada (embedded) de manera profunda en las relaciones sociales, por lo que la noción de salud no significaba una esfera privada sino una relación social. Las ideas de Lindemann se entienden mejor si atendemos la distinción del término enfermedad como disease y como illness. La primera se concibe como una realidad biológica independiente, tal como la aborda la medicina profesional; la segunda, como una condición subjetiva, esto es, la percepción que las personas tienen de la patología que las trastorna y afecta. (Lindemann, 1999, p. 8) La noción de enfermedad en esta segunda acepción, está relacionada con la manera de entender la interacción entre agentes bio-patógenos, procesos sociales y agencia humana. Es decir, la enfermedad no se concibe aislada de las decisiones humanas ni de sus efectos en el ámbito de la cultura y la vida cotidiana (Pérez, 1998, p. 164).

Desde esta acepción, cualquier epidemia, como dice David Arnold (1986) en cuanto microorganismo no tiene ningún significado, lo adquiere de su contexto humano, "por las formas en que se infiltra en las vidas de las personas, de las reacciones que provoca, y de la manera en que da expresión a los valores culturales y políticos" (p. 151) del momento. Por ejemplo, durante las llamadas pestes europeas, en las ciudades afectadas se impusieron cuarentenas, se sanitizaron bienes particulares y públicos, se evitaron asambleas públicas y religiosas, se puso especial atención en aislar a los enfermos y en especializar las prácticas funerarias (Gottfried, 1989, p.110-111; Lindemann, 1999, p. 46). También, se favoreció el conocimiento público de cómo cuidarse de las enfermedades epidémicas a través de escritos, folletos, cartillas y todo aquel medio de difusión de un saber público generalizado. Estas prácticas también fueron comunes en la población novohispana (Peniche, 2016, p. 23 y 57). Podríamos decir que fueron prácticas de la salud de la gente común.

Es verdad que es difícil aseverar que las pestes que azotaron Europa menguaron sólo por las cuarentenas, las medidas sanitarias públicas, el cambio del ambiente urbano (la piedra y el ladrillo sustituyó la madera, la paja y aserrín) y de las rutas comerciales euroasiáticas o la construcción de mayores obras de drenaje. Cierto que no habría que 
exagerar que las prácticas sociales fueron la causa de esta disminución. Como bien dice Lindemann, es muy probable que la disminución de cultivos y la consiguiente dislocación económica, producto de cambios climáticos, haya limitado los diferentes cruces humanos que propiciaban el contagio. (Lindemann, 1999, p. 47) Si la densidad de población y su forma de interactuar es un factor relevante para la propagación de enfermedades, la disminución de población en puertos comerciales puso un dique a las epidemias (Gottfried, 1989, p.101-102).

Lo que sí fue un hecho, es que el movimiento higienista logró que la gestión municipal se persuadiera de la necesidad de establecer ciertas prácticas para mantener la salud pública. En Alemania la ciudad de Nuremberg fue la menos afectada por la peste negra del siglo XIV. El factor decisivo de ello fue la práctica de su higiene pública (Gottfried, 1989, p.148-149). No fue un proceso fácil, ni tampoco lineal. Había resistencias y disputas políticas. Como las que libró el médico vegetariano John Snow, héroe de la novela de Steven Johnson (2020) quien tuvo que enfrentarse a la ceguera médico profesional y gubernamental de la Inglaterra de la mitad siglo XIX para convencerlos de la necesidad de un sistema sanitario basado en evidencias científicas contra la epidemia del cólera. (Vinten-Johansen et. al. 2003). Esa es quizás la razón por la cual en Francia los sistemas de alcantarillado a finales del siglo XIX y principios del XX, estaban atrasados con respecto a la experiencia británica que había propuesto Edwin Chadwick (Frioux, 2013).

Ahora bien, aunque el movimiento higienista tiene relevancia en la historia de las epidemias no estaría tan seguro como dicen algunos, que la idea de salud pública sea un invento de la ilustración (Pickstone, 1992) y la medicina moderna. En los hechos, la población del siglo XIII era más higiénica que la del siglo XVII (Duby, 1995, p. 89) por la sencilla razón de que la industrialización y sus efectos nocivos (contaminación, pestilencia, pauperismo, hacinamiento) jugaron un papel al impedir la higiene. De hecho, la medicina moderna no acabó con la peste del siglo XIV, sino fue controlada por leyes de salud pública decretadas en Italia y posteriormente en Europa, por las juntas municipales de sanidad, siguiendo el modelo de higiene pública de la ciudad de Nuremberg (Gottfried, 1989, p. 246 y ss.). Los médicos una vez legitimada su profesión, 
conformaron parte de la burocracia estatal encargada de vigilar la higiene que la gente común ya practicaba de por sí.

La tesis que sostengo de las prácticas de la gente común adquiere fuerza en la medida en que se escudriña la manera cómo esta ha enfrentado enfermedades epidémicas. En África, con todas las limitaciones que se quiera, son comunes las cuarentenas, el énfasis en higiene, el distanciamiento físico, la abstinencia sexual, la limitación al consumo de carne y otras prácticas como el modelo de convivencia entre enfermos o los procesos post-enfermedad, todos derivadas de su aprendizaje con las epidemias que han sufrido en todo el siglo XX y el que sigue en curso. Por prácticas de la gente común quiero decir, en este caso, acciones ante enfermedades, justificadas en función del cuidado colectivo. El criterio que debería seguirse para comprender las prácticas de la gente común, es que estas remiten a un sentido moral sobre el contenido y la autonomía de las mismas. Es lo que E. P. Thompson llamó economía moral de la multitud (Thompson, 1995, p. 380), prácticas antiutilitaristas o acciones contra la mentalidad industrial.

No debería entenderse por prácticas de la gente común una especie de ajuste perfecto entre el ambiente y esta, derivado de un virtuosismo filosófico. Además de tolerar la incertidumbre (con las pandemias nunca se sabe) y una buena dosis de realismo, se debe agregar al criterio del concepto de gente común que toda práctica es histórica y compleja. Esto quiere decir que los patrones de todo comportamiento no permanecen indefinidamente y que los cambios culturales o las innovaciones no son producto directo de la personalidad moral de los individuos. "La personalidad es moldeada por la cultura, pero nunca se ha demostrado que la cultura sea afectada por la personalidad" (Steward, 2014, p. 29), sobre todo en sociedades heterogéneas y con una diferenciación compleja.

Sin aspirar a cualquier tipo de universalismo, quiero discutir que las prácticas de la gente común podrían ser más efectivas ante un riesgo como el del actual SARS-CoV-2 si se tornan prácticas convivenciales. Lo convivencial de una sociedad es la capacidad de sus miembros para determinar de manera normativa, los umbrales nocivos de cualquier herramienta (motor, sistema de drenaje, automóvil, televisión, minas, escuela, hospital, leyes, fábricas, internet). Entonces, si convivencial es la sociedad en la que las personas 
controlan sus herramientas, cualquiera de estas, creada en esta perspectiva, tendría que tener un criterio para determinar los umbrales nocivos de la misma.

La convivencialidad es un concepto que acuñó Iván Ilich (2006). De él, retomo la siguiente hipótesis: "existen características técnicas en los medios de producción que hacen imposible su control en un proceso político. Sólo una sociedad que acepte la necesidad de escoger un techo común de ciertas dimensiones técnicas en sus medios de producción tiene alternativas políticas" (Illich, 2006, p. 369). El techo común del que hablaba Illich tiene una base normativa. Para lograrlo, se requiere establecer una serie de criterios morales con los que la gente común evaluaría las dimensiones técnicas de una sociedad.

En la actual situación pandémica que nos encontramos, la gestión empresarial con que gobiernos y corporativos están administrándola, no establecerán ningún criterio moral para controlarla, sino aparatos institucionales construidos bajo la forma de la mentalidad industrial: el estado de excepción y la medicina industrial ${ }^{11}$ (El axioma $d$ y $e$ de Ulrich Beck). La actual medicina industrial inhibe toda capacidad creativa y normativa de las personas para el autocuidado y el de los demás. Si como dice Iván Illich, la salud "designa la capacidad de adaptarse a ambientes cambiantes, de crecer, de madurar y envejecer; de curarse cuando está uno lesionado, sufrir y esperar pacíficamente la muerte" (Ilich, 2006a, p. 758), la medicina profesional no busca preservar la salud sino tratar enfermedades (Pérez, 2015, p. 85). Al dominar la cultura popular sobre el cuidado, la sanidad y la muerte, la mentalidad industrial de la medicina profesional niega el dolor, la enfermedad y la muerte al considerarlos males a erradicar. Por tanto, despoja el contenido moral que contiene la idea de salud, curar o cuidarse en un sentido sanitario.

La medicina industrial basa su éxito en su nocividad: el diagnóstico de enfermedades crónicas "es decir, de enfermedades que se diagnostican en base a la percepción médico-técnica, sin que existan terapias eficaces para su tratamiento ni se prevea tan siquiera disponer de ellas" (Beck, 1998, p. 259). Ruy Pérez Tamayo tiene reflexiones profundas y honestas a propósito de esto:

11 Véase nota 8. 
Las enfermedades crónicas son un recordatorio de lo poco que hemos aprendido los médicos sobre los mecanismos íntimos de los procesos patológicos, son una exhibición lastimosa y pública de nuestra incapacidad profesional, son la condena definitiva de la actitud equivocada de la profesión médica, que ha puesto todo su interés y énfasis en la terapéutica curativa. (Pérez, 2015, p. 85)

Para crear y mantener la autonomía en la orientación de nuestras acciones en tiempos de pánico-control generalizado, hay que desprofesionalizar y desmedicalizar el cuidado de la salud; esto permitiría que los auxilios terapéuticos y las habilidades para la observancia y la asistencia a la salud sean convivenciales. Sostengo la idea de que enfrentar la actual pandemia de SARS-Cov-2 es un asunto más de convivencialidad, que de progreso médico moderno, es decir, es una cuestión normativa y política que responde a la pregunta ¿Cómo cuidarnos en tiempo de pandemia global y en medio de la desesperación de los expertos por mantener el control social?

Nada de lo dicho hasta aquí debe entenderse como juicios que se opongan a la atención médica especializada, las innovaciones terapéuticas, los fondos públicos para propósitos curativos o la tecnología para tratar alguna disease. La discusión es el tema de la salud, el cuidado y la reflexión colectiva sobre la illness frente a la gestión empresarial de la pandemia del SARS-CoV-2. El punto no es tratar enfermedades, sino cuidar la salud. De ahí que la cuestión normativa de las prácticas convivenciales pasa por contrarrestar la mentalidad industrial. Para comenzar su construcción se necesita trabajar en ello bajo el supuesto de que sus prácticas son históricas y complejas. Se podría comenzar por el techo común del que hablaba Illich, esto es, establecer una serie de criterios morales con los que se evaluarían las dimensiones técnicas de una sociedad en términos de prácticas de la gente común.

a) Desconfiar de los especialistas y la certificación

Las profesiones generan expertos. Los profesionistas desarrollan habilidades técnicas más que actitudes éticas. Esta es la razón por la que un experto no sabe de umbrales o límites de las herramientas. Por lo regular es adoctrinado en el ideal del progreso; habla como un intoxicado del mercado y la industria. Las profesiones no 
generan convivencialidad porque atentan contra la autonomía de las personas y su creatividad. Su trabajo es "ocuparse de la gente" (Ilich, 2008, p. 35). Por su parte, la escuela impone saberes y prácticas. Certifica el valor de cada persona en el mercado, por ello genera desigualdad, segregación social y divide el mundo entre exitosos y fracasados. La escuela no procura ni potencia el reconocimiento (amor, estima, solidaridad) ni desarrolla la capacidad de cada quien para moldear su porvenir.

\section{b) Construir gramáticas morales}

El derecho y las normas sociales vigentes, no siempre orientan la decisiones y acción de las personas hacia una vida lograda. Las razones y las prácticas de los valores de la equidad, la autonomía creadora, la viabilidad y la justicia (gramáticas morales), creadas por la gente común, son parte imprescindible para construir herramientas convivenciales. Las gramáticas morales se derivan de prácticas cuyo contenido se forma a partir de lo que los sujetos hacen y dicen, cuando evalúan y critican determinadas relaciones sociales o situaciones que consideran injustas. Al ser prácticas convivenciales, sus experiencias morales trascienden a la sociedad al apuntar a nuevas formas de convivencia basadas en ideas y valores sobre lo que es justo, correcto, digno o con mayor libertad social.

\section{d) Poner fin al trabajo}

Trabajar es Tripaliare, esto es torturar. El trabajo supone siempre una relación subordinada: que una persona imponga a otra un deseo o un fin. En la sociedad del trabajo, este es más nocivo por el estado mental que subyace en él: ganar tiempo, reducir el espacio, aumentar la energía, multiplicar los bienes, prolongar la vida humana y satisfacer los deseos infinitamente. Esta mentalidad industrial destruye las economías morales, las bases del reconocimiento, las normas del común y deja sin posibilidad el imaginar y crear la convivencialidad. 
e) Contra el consumo obligatorio

La estratificación o el status social promueve los valores capitalistas: competencia y consumo. Estos valores presionan la voluntad y las acciones de los sujetos para insertarse de manera sumisa en el mercado realmente existente: la escuela, la fábrica, el supermercado, la institución pública o privada, todas estas propias de la mentalidad industrial. En este tipo de consumo se aprende a valorar la jerarquía y la disciplina como un bien a consumir. "Hasta nuestros días, el desarrollo económico significó siempre que la gente, en lugar de hacer una cosa, estaría en posibilidad de comprarla". (Ilich, 2008, p. 37) De esta manera se incapacita para interactuar de manera autónoma con el entorno debido a que los expertos y profesionales mediatizan toda acción convivencial: proponen el uso de tecnologías en vez de aprender oficios; recomiendan la escuela en vez de la biblioteca; promueven los supermercados y no los huertos colectivos; incentivan las industrias de comida rápida y no la preparación colectiva de alimentos.

a) Promover la práctica social de lo que es común inapropiable

Pensar por cuenta propia, sin restricciones ni cercos coercitivos para la expresión pública, son el núcleo de la democracia como herramienta convivencial. En ella la autonomía es el principio rector porque lo que se va a construir democráticamente siempre es indeterminable. En esta práctica social no existe la representación, porque esta es una figura ficticia de la política profesional. Pero lo más importante de esta práctica es que lo común no se entiende en un sentido de propiedad (pública), sino como una relación de vida nuda (sin derechos) donde la apropiación sea desactivada de las relaciones sociales. De esta manera la mentalidad industrial queda sin posibilidades de seguir existiendo. 
Estos y otros criterios morales serían herramientas para la convivencialidad. Y podrían descubrirse y crearse otras tantas, pero jamás poseerlas o monopolizarlas. (Ilich, 2006, p. 401). Esta es la razón por la que los profesionistas o expertos no tendrían razón de ser en una sociedad convivencial. Como las herramientas convivenciales no se conciben como instrumentos burocráticos para detener la corrupción, corregir políticas públicas o como programas políticos para apropiarse de los medios de producción y cambiar sistemas políticos, aquellos no se necesitan. Crear herramientas convivenciales es imaginar y crear otra vida social por lo que las prácticas de la mentalidad industrial serían desplazadas.

Con respecto al tema central del artículo, a diferencia de la gestión empresarial de la actual pandemia, una sociedad convivencial sí tomaría en serio la gran matanza de animales y la capacidad para el cuidado colectivo ante el SARS-Cov-2. Pero habrá que ser sinceros: la sociedad convivencial no existe y no sabemos si estamos a tiempo de elegir un modo de producción convivencial o ya es demasiado tarde. Pienso que debemos intentarlo y que, al hacerlo, el camino tendría que ser también convivencial y con los criterios y limitaciones antes descritos. Es decir, analizar la catástrofe y la posibilidad de salir de esta no como experto sino como miembros de una comunidad, como gente común que asume el riesgo de construir y orientar su vida personal con los demás humanos y no humanos.

\section{Consideraciones finales}

Este no es un artículo sobre el tema de los derechos de los animales, mucho menos sobre las políticas del bienestar animal. Considero que, si alguna consideración se tiene a los animales no humanos, uno debería comenzar por cuestionar las prácticas de los amantes y aficionados de estos seres por pertenecer al repertorio de la mentalidad industrial. Sólo un dato al respecto: los estadounidenses hacia los años noventa poseían "66 millones de gatos, 58 millones de perros, 40 millones de pájaros, 13 millones de animales pequeños (hámsters, gerbos, ratas, ratones, conejillos de Indias, conejos, hurones), 11 millones de peces de agua dulce y un millón de agua salada y 7.4 millones 
de reptiles (tortugas, iguanas, camaleones) que dan un total aproximado de 200 millones de animales" (Danten, 2008, p. 41). De los países que siguen el ejemplo de Estados Unidos son Alemania, Francia y Rusia. Contrario a lo que comúnmente se piensa, estas prácticas derivadas de una mentalidad industrial son nocivas para la vida de estas especies.

Esto se debe a que, en su gran mayoría los animales "de compañía”, provienen de criaderos industriales legales o del mercado negro. En Estados Unidos esta actividad lucrativa cría "cada año 3.1 millones de perros pura sangre y 2.6 millones de perros cruzados" (Danten, 2008, p. 55) en condiciones muy parecidas a la de los animales de la industria ganadera: falta de higiene, sin ventilación, sobrepoblación, sin estímulo sensorial con el exterior, algunos con enfermedades y con comportamiento patológico. Esto se repite en Holanda, Bélgica, Filipinas, Argentina, Senegal, Honduras o el Salvador con otro tipo de animales como peces, aves o reptiles para exportación (Danten, 2008, p. 61 y ss.).

Una mentalidad industrial es incapaz de comprender que una sobrepoblación de mascotas trae consecuencias nocivas para la salud humana y los mismos animales no humanos. El amante de los animales sólo es capaz de ver el bienestar psicológico particular que genera poseerlos y así invisibiliza todos los efectos que desencadena su acción. Por ello para la mentalidad industrial vivir sin animales no humanos en casa, sobre todo de los que provienen de la cría industrial parece imposible.

Aunque debo reconocer en la filosofía vegana buenas razones para dejar de consumir carne, no escribí el artículo para promover su filosofía. Lo hice para discutir las prácticas de la industria global de la carne, la cual está destruyendo la vida en general, sea humana o no y, sobre todo, preparando la próxima pandemia. Ergo, independientemente de si se es vegano o no, participe o no en la defensa y derechos de los animales, si hay preocupación seria sobre la equidad, la sustentabilidad y la justicia, la discusión sobre el comer carne es más que pertinente (Riechmann, 2012, p. 41).

Seguir las prácticas de la industria global de la carne, es aumentar el riesgo generado desde hace más de 100 años, por los miles de millones de animales criados en granjas industriales expuestos a la crueldad, la explotación de las y los trabajadores de la 
ganadería industrial documentado por Upton Sinclair (2012) en 1906, la destrucción ambiental y el potencial zoonótico de esa industria para crear un Chernóbil mundial. Entonces, discutir lo que comemos no es un asunto de estilos de vida, sino una cuestión política y moral. De ahí que la pregunta de Jorge Riechmann sobre si los socialistas o comunistas del siglo XXI podrían seguir comiendo carne (Riechmann, 2012) no es retórica, como tampoco lo es interrogar si un ecologista, una feminista o las y los anticapitalistas, podrían dejar de hacerlo.

La mentalidad industrial es incapaz de comprender estas preguntas. La idea básica de que la influenza del virus H5N1 (Gripe aviar) nos puede matar si llegamos a contagiarnos y de que no podríamos contagiarnos si no tenemos interés en los pollos, es impensable para esta mentalidad. 0 la idea de que si nos enfermamos de SIDA estamos en riesgo de morir y de que probablemente no nos contagiemos si tenemos relaciones sexuales de riesgo con preservativos o practicamos la abstinencia ante una duda.

Estas preguntas plantean un debate serio porque la actual catástrofe es real. (Leakey y Lewin, 1997,151). A las amenazas derivadas del calentamiento global, la destrucción de ecosistemas o la deforestación, no hay manera de escapar. Con nuestra obsoleta mentalidad industrial nos hemos puesto en distintos riesgos y estos se reparten a todas y todos sin distinción, sea humanos y no humanos. La OMS, los grandes magnates y los gobiernos en turno quieren hacernos creer que el SARS-Cov-2 es responsabilidad de todos y por tanto todos "debemos trabajar juntos para enfrentarlo". Esta retórica es nociva porque no pretende cambiar el estado de cosas actual que origina la pandemia, por ejemplo, la gran matanza de animales.

Ante todo lo anterior, lo que aquí discuto es que las elecciones individuales y colectivas con autonomía son el mejor antídoto contra las catástrofes. Nada nos garantiza la inmunidad, pero si elegimos convivencialmente no comer carne, tener sexo con protección, no invadir "lugares exóticos", no cazar, cuestionar el dogma del crecimiento y el desarrollo económico, discutir en serio el gran consumo, con las herramientas convivenciales que se construyan, el escenario seguramente será otro. Entonces, sostengo que son las prácticas de la gente común y la convivencialidad las que podrían enfrentar la catástrofe derivada de la mentalidad industrial. 
Para acercarnos a una sociedad convivencial ha llegado la hora de hacer extensivo el consenso del fin del progreso. Hacer realidad aquella intuición que el Subsecretario de justicia del gobierno de Salvador Allende, María José Viera-Gallo, luego de tener encuentros con Iván Ilich, escribiera en 1972 en el diario chileno La Tercera. Al final del artículo Viera-Gallo escribió la frase "el socialismo sólo puede llegar en bicicleta" que en los últimos años ha inspirado a no pocos intelectuales y ecologistas de las metrópolis. En realidad, es la idea de convivencialidad de Iván Ilich; no el socialismo, sino la capacidad de la gente común para determinar de manera normativa, los umbrales nocivos de cualquier herramienta.

Por último, no es este un texto sobre el conservacionismo o el cuidado de la naturaleza en un sentido teológico o metafísico. Si no sitúo a la naturaleza "afuera" de la sociedad, tampoco la concibo con intencionalidad, ni supongo que existe un equilibrio en ella. Por tanto, la idea de controlarla o entenderla como víctima que en estos momentos se está vengando es un disparate. Prefiero entenderla y aceptarla como lo hacen los paleontólogos Richard E. Leakey y Roger Lewin, “con su variedad infinita y sus procesos infinitamente complejos" (Leakey y Lewin, 1997, p. 108).

Por eso la gran matanza de animales que en nuestro sistema mundo capitalista crea epidemias y catástrofes, no me motiva a defenderlos y/o preservarlos. Tampoco a conservar la naturaleza. Esto es parte de la mentalidad industrial: apropiarse de ella para su beneficio, cualquiera que este sea. En todo caso, si alguna consideración ética o moral tuviera por los animales no humanos y la naturaleza, en la medida de poder hacerlo, los dejaría en paz.

En suma, es verdad que la extinción en masa es un fenómeno estudiado. También que las epidemias han ocurrido con antelación y que numerosas muertes humanas por diversas enfermedades ocurren cada año. Sin embargo, las características del actual SARS-Cov-2 como hecho social total, nos acerca más como realidad que como ficción literaria a lo que Jared Diamond (2015) llama colapso y Leakey y Lewin (1997) extinción. La gran matanza de animales y la mentalidad industrial aportan material a esas características. Valdría la pena discutirlo con mayor seriedad, o de plano declararnos cínicos, incompetentes o como dijeran Leakey y Lewin, muertos en vida (Leakey y Lewin, 1997, p. 162). 


\section{Bibliografía}

AMENGUAL Coll, Gabriel (2001). La moral como derecho. Estudio sobre la moralidad en la Filosofía del Derecho de Hegel. Madrid: Trotta.

APPLEBY PN \& KEY TJ. (2016). The long-term health of vegetarians and vegans. Proc Nutr Soc. 75(3) pp. 287-293. doi:10.1017/S0029665115004334

ARNOLD David (1986). Cholera and Colonialism in British India. Past \& Present, No. 113 (November), pp. 118-151.

BECK Ulrich (1998) La sociedad del riesgo. Hacia una nueva modernidad. Barcelona: Paidós.

BENTHAM Jeremy (1979). Introduction to the principles of Morals and Legislation. University of London: The Athlone Press.

BONDESON, Jan (2000). La sirena de Fiji y otros ensayos sobre historia natural y no natural. México: Siglo XXI.

BORKENHAGEN LK, Salman MD, Ma MJ, Gray GC (2019). Animal influenza virus infections in humans: A commentary. Int J Infect Dis. (88) pp. 113-119.

doi:10.1016/j.ijid.2019.08.002

BRONCANO, Fernando (2000). Mundos artificiales. Filosofía del cambio tecnológico. México: Paidós/FFyL UNAM.

BUJ Buj Antonio (2005). Viejas y nuevas plagas. Una mirada crítica a los riesgos biológicos en los inicios del siglo XXI. Cuadernos geográficos de la Universidad de Granada, Vol. 36, № 1, 2005 pp. 577-584.

BUNGE, Mario (1976). Ética y ciencia. Buenos Aires: Siglo XX.

CARSON Rachel (2017). Primavera silenciosa. México: Booket.

COLLINS Chuck (2020). "The combined wealth of Amazon's Jeff Bezos and Facebook's Mark Zuckerberg has climbed by nearly $\$ 60$ billion in the last two months". Institute for Policy Studies. https://ips-dc.org/us-billionaire-wealth-surges-434-billion-asunemployment-filers-top-38-million/

CORKERY Michael \& YAFFE-BELLANY David (2020). Meat Plant Closures Mean Pigs Are Gassed or Shot Instead, The New York Times.

CRAWFORD Dorothy H. (2000). The Invisible Enemy: A Natural History of Viruses. Oxford: Oxford University Press. 
CRUZ Vargas, Juan Carlos (2020). Las presiones de la industria automotriz. Revista Proceso, 227217 de mayo.

DANTEN, Charles (2008). Un veterinario encolerizado. Ensayo sobre la condición animal. México: Fondo de Cultura Económica.

DARNTON Robert (2015). La gran matanza de gatos y otros episodios en la historia de la cultura francesa. México: FCE.

DE LORA, Pablo (2003). Justicia para los animales. La ética más allá de la humanidad. Madrid: Alianza Editorial.

DENNER J. (2019). Hepatitis E virus (HEV)-The Future. Viruses. 11 (3):251. doi:10.3390/v11030251

DIAMOND, Jared (2019). Colapso. ¿Por qué unas sociedades perduran y otras desaparecen? Barcelona: Penguin/Random House.

DOHERTY Peter C. (2019). Pandemias: todo que necesitas saber. Buenos Aires: Autoría Editorial.

DUBY, Georges (1995). Año 1000, Año 2000. La huella de nuestros miedos. Santiago: Editorial Andrés Bello.

ELSTER, J. (2010). La explicación del comportamiento social. Más tuercas y tornillos para las ciencias sociales. Barcelona: Gedisa.

ERMAKOFF, Ivan (2019). Sobre los límites de la elección racional, en Benzecry Claudio E., Krause Monika y Reed Isaac A. La teoría social, ahora. Nuevas corrientes, nuevas discusiones. Buenos Aires: Siglo XXI.

EVANS E. P. (1906). The criminal prosecution and capital punishment of animals. London: W. Heinemann.

FRIOUX, Stéphane (2013). Les batailles de l'hygiène. Villes et environnement de Pasteur aux Trente Glorieuses, Paris: Presses universitaires de France.

GARRETT, Laurie (2006). La próxima pandemia, Salud Pública, 48 (3) pp.268-227. Disponible en http://saludpublica.mx/index.php/spm/article/view/6695/8342

GOTTFRIED Robert S. (1989). La muerte negra: desastres naturales y humanos en la Europa medieval. México: FCE.

HEGEL G. W. F. (2005). Principios de la filosofía del derecho (traducción y prólogo de Juan Luis Vermal). Barcelona: Edhasa. 
HIRSCHMAN, Albert O. (1978). Las pasiones y los intereses. Argumentos políticos en favor del capitalismo antes de su triunfo. México: FCE, México.

HOLMES, Eddie (2009). The Evolution and Emergence of RNA viruses. Oxford, 2009.

HORKHEIMER Max y ADORNO Th. W. (2005). Dialéctica de la Ilustración. Madrid: Trotta.

HORKHEIMER Max y ADORNO Th. W. (2014). Hacia un nuevo manifiesto. Buenos Aires: Eterna cadencia editora.

HUME, David (1977). Tratado de la naturaleza humana. Madrid: Editora Nacional.

ILLICH, Iván (2006). La convivencialidad. Obras reunidas I. México: Fondo de Cultura Económica.

ILLICH Iván (2006a). Némesis médica. Obras reunidas I. México: Fondo de Cultura Económica.

ILLICH Iván (2008) El trabajo fantasma. Obras reunidas II. México: Fondo de Cultura Económica.

JOHNSON Steven (2020). El mapa fantasma. La epidemia que cambió la ciencia, las ciudades y el mundo moderno. Madrid: Capitán Swing.

LEAKEY Richard E. y LEWIN Roger (1997). La sexta extinción. El futuro de la vida y de la humanidad. Barcelona: Tusquets.

LE GOFF Jacques (1974). "Las mentalidades. Una historia ambigua”. En Jacques Le Goff y Pierre Nora. Hacer la historia. Vol. III, Barcelona: Editorial LAIA. pp. 81-98

LINDEMANN, Mary (1999). Medicine and society in early modern Europe. United Kingdom: Cambridge University Press.

LUCANO Ramírez, Hilda Nely (2017). A favor de los animales. Fragmentos filosóficos contra el especismo. México: CU-Lagos/Universidad de Guadalajara.

LUXEMBURGO, Rosa (2019). Cartas de la prisión. Madrid. Akal.

MARCUSE, H. (1973) Contrarrevolución y Revuelta. México: Joaquín Mortiz.

MARCUSE H. (2011). La sociedad carnívora (Traducción de Miguel Grinberg). Buenos Aires: Ediciones Godot Argentina.

MCNEILL, William H. (1976). Plagues and peoples. New York: Anchor Press/Doubleday

MEDELLÍN, Rodrigo y SURO Piñera David (2020). Los murciélagos no tienen la culpa. La Jornada 22 de junio disponible en

https://www.jornada.com.mx/2020/06/22/opinion/014a1pol 
MEDINA Manuel y SANMARTÍN José (Eds.) (1990). Ciencia, Tecnología y Sociedad. Estudios interdisciplinares en una universidad en la educación y en la gestión pública. Barcelona: Anthropos.

MENCHERO Sánchez, M. (2020). Flujos turísticos, geopolítica y COVID-19: cuando los turistas internacionales son vectores de transmisión. Geopolítica(s). Revista de estudios sobre espacio y poder, 11(Especial), 105-114.

MITCHAM, Carl (1990). En busca de una nueva relación entre ciencia, tecnología y sociedad. en Manuel Medina y José Sanmartín (Eds.), Ciencia, Tecnología y Sociedad. Estudios interdisciplinares en una universidad en la educación y en la gestión pública. Barcelona: Anthropos.

MOSTERÍN, Jesús (2014). El triunfo de la compasión. Nuestra relación con otros animales. Madrid: Alianza Editorial.

NIERENBERG Danielle (2006). Reconsiderando la industria cárnica mundial, en La situación del mundo 2006. Eje principal: China e India. Barcelona: Worldwatch Institute/ Editorial Icaria.

OLDSTONE Michael B. A. (1998) Viruses, plagues, and history. Oxford: Oxford University Press.

PALMER, M. K. (1982). Rational Action in Economic and Social Theory. Some Misunderstandings. European Journal of Sociology, 23 (I): 179-197.

PENICHE Moreno Paola (2016). El cólera morbus en Yucatán. Medicina y salud pública, 1833-1853. México: Miguel Ángel Porrúa/CIESAS.

PÉREZ Tamayo Ruy (1998). Enfermedades viejas y enfermedades nuevas. México: Siglo XXI.

PÉREZ Tamayo Ruy (2015). Serendipia. Ensayos sobre ciencia, medicina y otros sueños. México: Siglo XXI.

PICKSTONE John V. (1992). "Dearth, dirt and fever epidemics: rewriting the history of British 'public health', 1780-1850” en Terence Ranger \& Paul Slack (eds.) Epidemics and ideas: essays on the historical perception of pestilence. Cambridge: Cambridge University Press.

PLUTARCO (2002). Obras morales y de costumbre. (Moralia) IX (introducciones, traducciones y notas por Vicente Ramón Palerm y Jorge Bergua Cavero). Madrid: Gredos.

POLANYI, Karl (2014). Los límites del mercado. Reflexiones sobre economía, antropología y democracia. Madrid: Capitán Swing.

PONTING, Clive (1992). Historia verde del mundo. Barcelona: Paidós.

PORFIRIO de Tiro (1984). Sobre la abstinencia. España: Gredos. 
QUAMMEN David (2020). Contagio: la evolución de las pandemias. Barcelona: Debate. [Kindle DX version]. Retrieved from Amazon.com.

QUINTANILLA, Miguel Ángel (2005). Tecnología: un enfoque filosófico y otros ensayos de filosofía de la tecnología. México: FCE.

RAMONET, Ignacio (2020). La pandemia y el sistema-mundo en La Jornada 25 de abril. Disponible en https://www.jornada.com.mx/ultimas/mundo/2020/04/25/ante-lodesconocido-la-pandemia-y-el-sistema-mundo-7878.html\#sdfootnote58anc

REGAN, Tom (2016). En defensa de los derechos de los animales. México: FCE/UNAM/IIF/Programa Universitario de Bioética.

RIBEIRO Silvia (2020). Gestando la próxima pandemia. La Jornada 25 de abril. Disponible en https://www.jornada.com.mx/2020/04/25/opinion/023a1eco

RIECHMANN, Jorge (2005). Todos los animales somos hermanos. Ensayo sobre el lugar de los animales en las sociedades industrializadas. Madrid: Los Libros de la Catarata.

RIECHMANN Jorge (2012) ¿Pueden un socialista o una comunista del siglo XXI no ser vegetarianos? Viento Sur Número 125/Noviembre. 40-50.

https://vientosur.info/spip.php?article7670

ROUDINESCO, Elisabeth (2009). Y mañana, qué... / Elisabeth Roudinesco y Jacques Derrida. Buenos Aires: Fondo de Cultura Económica.

SARACHO López, F. J. (2020). Espacialidad y pandemia: La crisis del coronavirus vista desde la geopolítica negativa. Geopolítica(s). Revista de estudios sobre espacio y poder, 11(Especial), 69-79.

SCHOPENHAUER Arthur (1967). Alrededor de la filosofía. Valencia: Prometeo.

SOTOMAYOR, Gabriela (2020). México combate a ciegas la pandemia. Revista Proceso, 2272, mayo.

STEINFELD Henning et. al (2009). La larga sombra del ganado: problemas ambientales y opciones. Roma: FAO.

STEWARD, Julian H. (2014). Teoría del cambio cultural. México:

CIESAS/UAM/Universidad Iberoamericana.

TAINTER, Joseph A. (1988). The Collapse of Complex Societies. Cambridge: Cambridge University Press.

The Center for Food Security and Public (2016). Nipah Virus Infection. disponible en http://www.cfsph.iastate.edu/Factsheets/pdfs/nipah.pdf

THOMPSON, E. P. (1995). Costumbres en común. Barcelona: Crítica. 
TOLSTOI, León (1902) Placeres crueles (traducción de Augusto Riera) Barcelona: Casa Editorial Maucci.

UPTON Sinclair (2012). La jungla. Madrid: Capitán Swing.

VINTEN-JOHANSEN Peter, Brody Howard, Paneth Nigel, Rackman Stephen \& Rip Michael (with David Zuck) (2003). Cholera, Chloroform and the Science of Medicine: A Life of John Snow. New York: Oxford University Press.

VIVAS, E. (2012) "Puerca industria”. Le Monde Diplomatique, 197. Disponible en http://esthervivas.com/2012/03/21/puerca-industria/

WALKER Brian (1989). Diversity and stability in ecosystem conservation, en David Western y Mary Pearl (eds.). Conservation for the Twenty-first Century. New York: Oxford University Press.

WALLACE, Rob (2016). Big farms make big flu. Dispatches on infectious disease, agribusiness, and the nature of science. New York: Monthly Review Press.

WALLACE, Rob (2020). Notes on a novel coronavirus. Disponible en https://mronline.org/2020/01/29/notes-on-a-novel-coronavirus/

WENHUI Li, Swee-Kee Wong, Fang Li, Jens H. Kuhn, I-Chueh Huang, Hyeryun Choe, Michael Farzan (2006) Animal Origins of the Severe Acute Respiratory Syndrome Coronavirus: Insight from ACE2-S-Protein Interactions. Journal of Virology 80 (9) pp. 4211-4219; DOI: 10.1128/JVI.80.9.4211-4219.2006

WOLF, Eric R. (2005). Europa y la gente sin historia. México: FCE

WOLFE ND, Daszak P, Kilpatrick AM, Burke DS (2005). Bushmeat hunting, deforestation, and prediction of zoonoses emergence. Emerging Infectious Diseases. Dec;11(12) pp. 1822-1827. DOI: 10.3201/eid1112.040789. 